4. Тысяча убитых россиянок. Фемицид - кто виноват и что делать? Любава Малышева 12.10.2019 Радио свобода;

5. Туфли из Стамбула. Патрисия Помпала - о домашнем насилии. Патрисия Помпала. 11.10.2019 Радио свобода;

6. Женщины и мужчины россии.2018» сборник федеральной службы государственной статистики;

7. Наедине с врагом - Марьяна Торочешникова 13.08.2019- Радио свобода;

8. Виктимологический аспект поведения женщин - жертв преступления. Банных Е.Н.- Дис. Канд. Юрид. Наук: 12.00.08. Челябинск, 2006175 с. РГБ ОД 61:06-12/1431;

9. Лихаева О.В. Латентная жертва насильственных преступлений, совершаемых в сфере семейных отношений: дис. Канд. Юрид. Наук: 12.00.08 Тюмень, 2006203 с. РГБОД, 61:07-12/160;

10. Дело сестер Хачатурян: отвечаем на главные вопросы - Нина Назарова, Анна Чернова 26.06.2019 - Би би си.

\title{
Зорилэ Д.В. \\ К вопросу о применении гуманитарно-научных методов в процессе анализа историко-правовых источников
}

Российский химико-технологический университет им. Д.И. Менделеева (Россия, Москва)

doi: $10.18411 / 1 j-07-2021-81$

\section{Аннотация}

В статье рассматривается вопрос применения в историко-правовых исследованиях методологии, получившей развитие в смежных гуманитарных дисциплинах - в молодой области - юрислингвистике, а также в ставшем традиционном направлении - компаративистике, развивающей комплекс сравнительных методов и подходов. Анализируются особенности применения соответствующего методологического инструментария в процессе интерпретации текстов историко-правовой направленности, в частности, проблемы адекватного перевода зарубежных источников, в первую очередь - правовой терминологии. В статье использованы работы как известных теоретиков соответствующих направлений 19 века, так и современных авторов; приведены примеры практической работы с текстами юридической направленности на иностранном зыке.

Ключевые слова: язык, юрислингвистика, компаративистика, анализ текста, перевод.

\section{Abstract}

The article deals with the involving into the history of law the methodology of a new branch - jurislinguistics and of a traditional one - comparativistics, which supply methodological approaches to the historical investigations. The features of its implementation in order to a correct translation of foreign legal texts and interpretation of their terminology are described. Investigations of authors of 19-th century and modern scientists are involved; also - examples of interpretation of juridical texts in foreign languages.

Keywords: language, jurislinguistics, comparativistic, text analyze, interpretation.

Исследование объективного права осуществляется посредством анализа массива правового материала, имеющего языковую форму выражения. Отечественная теория права выделяет специальный метод толкования - лингвистический - как необходимый этап освоения законодательства. Историко-правовое исследование основано на обращении к разнообразным текстам юридической направленности, что также предполагает их лингвистический анализ. Применение метода лингвистического анализа текстов нормативно-правовых актов и иных правовых источников выводит на связь юриспруденции и лингвистики. Связь этих областей знания как отдельную проблему правовой науки обозначил советский правовед А.А. Ушаков, развивавший 
направление правовой лингвистики в рамках родного языка. А.А. Ушаков исследовал историю языка права, законодательный стиль, предложив ввести понятие «законодательное литературное произведение» как объект лингвистического исследования [2]. В последнее десятилетие бурное развитие переживает самостоятельная область - юрислингвистика, получившая не только научное, но и учебно-методическое закрепление.

Предметом юрислингвистики выступает создание, функционирование специального юридического языка, способного обслуживать специальную правовую коммуникацию; естественный язык (язык обыденного общения) выступает при этом как элемент законотворческой деятельности и толкования закона. В задачи юрислингвистики наряду с другими входят такие направления, как терминологическое, переводческое, лексикографическое обеспечение юридической деятельности, методическое обеспечение судебно-лингвистической экспертизы. При интерпретации историко-правовых текстов применяются также сравнительный метод, который традиционно использовался в языкознании. «XIX столетие стало триумфом сравнительного метода в языкознании. Работы Ф. Боппа, Р. Раска, В. фон Гумбольдта, Я. Гримма доказали принципиальную применимость сравнения как метода в области гуманитарного научного знания, где эксперимент невозможен» [1, с. 99]. Методические приемы компаративистики не исчерпали себя; попытки комбинации лингвистических и юридических методов предпринимаются в современной компаративистике как самостоятельной научно-прикладной дисциплине [1, с. 99]. Два этих направления позволяют разнообразить также теоретико-методологическую базу переводческой деятельности в историко-правовых исследованиях.

В тексте на иностранном языке как предмете исследования историков зарубежного права приобретает большую актуальность проблема адекватного понимания и оценки юридического источника, независимо от конкретного «жанра» (закон, законопроект, стенографические отчеты заседаний органов власти, научные публикации, деловая переписка и т.д.). Здесь возникают вопросы как минимум его точного перевода и толкования иностранных юридических терминов и понятий. Подавляющее большинство правовых норм государств современного мира в качестве неотъемлемого признака предполагает такое качество, как формальная определенность. В свою очередь, критерий формальной определенности юридических норм подразумевает наличие писанной, словесной формы как основной формы выражения. Словесная форма выражения юридических норм определяется как лингвистическими особенностями национального языка, так и правилами юридической техники, регламентированными нормами национального права. «Следовательно, анализ правовых норм государства, область их применения и объем содержащейся в них информации, необходимо проводить в соответствии с их языковыми репрезентациями в тексте источников права конкретного государства как правовой основы построения общественных отношений» [1, с. 102]. Юридический текст на иностранном языке подлежит дополнительному этапу освоения: наряду с юридико-техническим и лингвистическим анализом, он подвергается переводу с иностранного языка. «Современные исследователи-юристы, обращая свое внимание на зарубежные источники права, очень мало внимания уделяют его содержанию, и еще меньше внимания уделяют деталям практики его применения потому, что, чаще всего они не обладают достаточной квалификацией в сфере лингвистики. В свою очередь профессиональные лингвисты, не имея специальной правовой подготовки, подготовки в вопросах юриспруденции вряд ли способны прийти к объективным и результативным выводам в правовых исследованиях. И конвергенция методов лингвистики и сравнительного правоведения может быть крайне полезной» [1, с. 100]. При вовлечении иностранных юридических текстов в отечественный научный оборот можно говорить о выделении двух составляющих процесса - собственно о переводе и интерпретации его 
специально-правовых особенностей (лексико-семантических, морфологических, синтаксических), связанных с спецификой правовой системы страны переводимого языка при учете ее состояния в соответствующий исторический период.

«Особого внимания требует изучение нормативного языка, правовой лингвистики, характерной для законодательства государств разных правовых семей. Сказываются особенности национального языка, его лингвистический строй. А отсюда - краткость или пространность, образность или математическая строгость, нормы полные или распыленные по разным статьям и параграфам» [7, с. 113]. Специфика истории зарубежного государства и права заключается в особенностях текстов: во многих случаях исследуется устаревший, архаичный материал, содержащий вышедшую из употребления лексику, понятия, терминологию, отсылающую к реалиям прошлого. Известный немецкий языковед и философ 19 века В. фон Гумбольдт утверждал: «Различные языки - это отнюдь не различные обозначения одной и той же вещи, а различные видения ее» [6, с. 349]. Правовая культура тесно связана с национальными особенностями, которые, в свою очередь, «зашифрованы» в языке: «С традициями и уровнем правовой культуры связан наибольший объем правовых различий. Конечно, приемы юридической техники и построения правовых актов значительно отражают специфические способы и элементы «юридической технологии», но в большей степени важно обеспечить их привычное социальное восприятие, отношение к ним граждан. Языковые культурологические особенности населения не могут не учитываться в полной мере» [7, с. 114]. Выделяется связка: национальная правовая культура - язык. В. фон Гумбольдт в своем программном труде «О различии строения человеческих языков и его влиянии на духовное развитие человечества» (1830-1835 гг.) писал об эпохе образования и учености как высшей ступени развития соответствующего языка и общества: «При своем успешном развитии дух достигает ступени, когда он, словно отбрасывая предчувствия и предположения, стремится поставить свое знание на прочную основу и свести его совокупность в единство. Наступает эпоха образования науки и развивающейся из нее учености, и этот момент не может не оказать величайшего воздействия на язык» [5, с. 187].

Сложность языковой системы проявляется, прежде всего, в её многомерности, то есть в наличии в ней ряда подсистем (уровней языка). Для объективации научных выводов, юридические материалы, фигурирующие в сравнительно - правовых исследованиях, необходимо пропускать через критерии лингвистических параметров исследования: 1) фонетико-фонологический; 2) морфемный; 3) лексико-семантический; 4) синтаксический $[1$, C. 98]. Задачи историко-правовых исследований требуют применения трех последних методов, среди которых преобладающее значение имеет лексико-семантический. Носителем профессиональной юридической информации является в первую очередь юридический термин, поэтому предпосылкой правильной оценки текста во многом является точный перевод юридической терминологии. Термин как научный инструмент обеспечивает исследователю адекватное восприятие юридического текста и юридически значимой информации неюридического текста [1, c. 101]. В. фон Гумбольдт в качестве показателя высокой степени цивилизованности народов выделяет признак развитости интеллектуальных понятий в целом: «Подлинная сфера разнообразия в смысловой наполненности слов - обозначение интеллектуальных понятий. Здесь редкое слово выражает то же понятие, что и слово в другом языке, без того или иного очень заметного отличия. Пока - например, изучая языки нецивилизованных и неразвившихся народов, - мы не имеем никакой возможности видеть тонкие смысловые нюансы, нам кажется, что значения слов в разных языках однообразны. Но внимательное обследование языков высокой культуры предохраняет нас от этого поспешного заключения» [5, с. 181]. Культурные и языковые, и, как следствие, терминологические различия иногда становятся не преодолимыми с помощью лингвистических соответствий. В частности, это отмечают авторы перевода 
Гражданского уложения Германии: «При подготовке этого текста пришлось столкнуться с серьезными проблемами терминологического характера. /.../ Поскольку возникающие расхождения в толковании едва ли поддаются полноценному возмещению, в книге широко используется аппарат примечаний и пояснений для облегчения понимания текста» [4, Предисловие, С. ҮII]. Аналогичные «трудности перевода» отмечают авторы перевода Гражданского кодекса Франции: «С целью более глубокого понимания положений Кодекса к переводу прилагаются подготовленные автором этой работы Словарь - справочник основных терминов с указателем, облегчающим их нахождение, исторические сведения о предтечах и главных участниках французской гражданско-правовой кодификации, а также краткий комментарий к предшествующему переводу Кодекса на русский язык. По мнению автора перевода, такой подход, сочетающий разнообразные справочные сведения, необходимые разъяснения и показ динамики положений Кодекса на протяжении всего двухвекового периода его существования, должен способствовать более основательному видению и дальнейшему плодотворному исследованию его правовой материи» [3, с. 3].

Характерные особенности фиксируются и в синтаксическом оформлении текстов, также отражающем уровень языковой культуры и мышления, что, в частности, отмечал В. фон Гумбольдт: «Гораздо больше, чем в отдельных словах, интеллектуальное своеобразие наций дает о себе знать при сочетании слов в речи, проявляясь в пространности, какую язык способен придать своим предложениям, и в степени разветвленности, какая может быть достигнута внутри определенных границ. Мы видим тут подлинную картину хода мысли и сцепления идей, за которыми речь не в силах поспеть, если язык не располагает необходимым богатством и широкой свободой сочетания своих элементов» [5, с. 182]. В. фон Гумбольдт так описывал взаимодействие практического применения языка (речи), языка как системы и мыслительной деятельности: «К самому акту обозначения понятия добавляется еще особая работа духа, переводящая понятие в определенную категорию мышления или речи, и полный смысл слова определяется одновременно понятийным выражением и /.../ модифицирующим обозначением. Но оба эти обозначения лежат в совершенно различных сферах. Обозначение понятия относится к области все более объективной практики языкового сознания, посредством которого единичный случай, индивидуальное слово, соотносится со всей совокупностью возможных случаев в языке и речи. Только посредством этой операции, осуществляемой в самых чистых и глубоких сферах и тесно связанной с самой сущностью языка, в последнем реализуется с надлежащей степенью синтеза и упорядочения связь его самостоятельной деятельности, обусловленной мышлением, и деятельности, обусловленной исключительно восприимчивостью и более связанной с внешними впечатлениями» [5, «О различии строения человеческих языков и его влиянии на духовное развитие человечества» (1830-1835 гг.), С. 118].

Позитивное право закрепляет механизмы политической власти, ее организацию и формы осуществления. Фактическая реализация юридических норм определяет политический режим, существующий в государстве на конкретном этапе его развития, соответствующий конкретным историческим условиям развития той или иной страны и языка национального общения. «Изучение правовых аспектов осуществления государственной власти, в значительной степени, представляет собой анализ языковых репрезентаций норм права. Язык является естественной средой бытования права, вне языка не существует права» [1, с. 101]. Переводчики Гражданского уложения Германии фиксируют: «Авторам Гражданского уложения удалось создать свод правил, который характеризуется безупречной системной завершенностью и точностью понятий. Однако это стремление к логической последовательности привело также к возникновению юридического языка, которому присуща высокая степень абстракции, 
что, в свою очередь, сделало этот язык зачастую недоступным для усвоения и понимания простыми гражданами. В целом это соответствовало намерениям авторов создать закон «юристам для юристов». Предполагалось, что при возникновении спора граждане для его разрешения воспользуются услугами специалиста, т.е. юриста. Поэтому Уложение в первую очередь адресовано юристам» [4, с. X, XI]. Авторы перевода указывают на средний класс, бюргеров как адресатов Гражданского уложения, отмечая, что «основополагающие принципы гражданско-правового мышления в 19 веке несли на себе отпечаток идей просвещения и либерализма». «Язык Уложения также ориентирован на бюргеров» [4, с. X; XI].

Современный антропоцентрический методологический подход в лингвистике явился отражением того постулата, что язык не может быть понят вне связи с его носителем, с человеком. Истоки «антропоцентризма» восходят к идеям В. фон Гумбольдта [1, с. 99]. В. фон Гумбольдт в написанной еще в 1818 году работе «Размышления о движущих причинах всемирной истории» выводит антропоцентризм на уровень общенационального взаимодействия отдельных носителей языка, придавая ему новое измерение. Автор исследует воздействие единичных, индивидуальных речевых практик на качественные характеристики языка как продукта общенационального творчества: «Исходя из внутренней природы многих языков греческого, латинского, итальянского, французского, - можно сказать, что долговечность, а тем самым и сохраняющаяся сила и красота языка зависят от того, что можно было бы назвать его материалом, от полноты и жизненной силы восприятия, и присущего людям, в груди и устах которых этот язык возник, а отнюдь не от культуры наций; что поэтому не может процветать язык, на котором говорит недостаточно большое число людей, и лишь языки тех народов, которые в течение ряда веков претерпевают удивительную судьбу, распространяются так далеко, что в них возникает как бы особый мир (это явствует, даже если не обращаться к истории, из грамматического, и прежде всего лексического, строя этих языков); и наконец, что язык всегда останавливается в своем развитии, как только нация в целом перестает жить деятельной внутренней жизнью в качестве массы, в качестве нации» [6, с. 289]. Применительно к анализу текста, содержащего специальную терминологию, в этой связи важно учитывать: различается индивидуальное, эвристическое применение лексической единицы-термина, свойственное отдельному субъекту (исследователю) в рамках его профессиональной деятельности, и устоявшееся словоупотребление в определенной профессиональной, научной сфере. В данном случае выделяется связка «текст источника - научная среда». Научная среда (научная школа) обеспечивает частотность и массовость применения термина, протяженную во времени, порой выходящем за рамки жизни отдельного индивида, своеобразную «апробацию» термина. Первое словоупотребление от второго возможно отличить лишь в сопоставлении с текстами представителей той же школы соответствующего исторического периода, то есть, применяя сравнительный метод. Адекватность перевода обеспечивается при использовании на языке перевода лексических единиц с аналогичными характеристиками.

Перевод объемных, сложно структурированных законодательных актов является не только этапом эвристической деятельности, но и ее отдельным видом, завершающим итогом которого является собственно перевод текста. Таковыми являются, в частности, упомянутые выше переводы Гражданского кодекса Франции, Гражданского уложения Германии $[3,4]$. Особенность данных двух источников заключается в том, что будучи принятыми в позапрошлом веке (Гражданский кодекс французов - 21 марта 1804 года, ГУГ - 18 августа 1896 года), они представляют интерес для историков права. Но одновременно они являются ныне действующими источниками права (с существенными изменениями), что значительно расширяет круг их читателей. При обращении к подобным источникам права решается задача адекватной оценки 
зарубежной правовой культуры и ее последующего вовлечения в отечественную правовую науку и, возможно, в практику - ведь «... не стоит недооценивать роль права как важного инструмента привнесения новых культурных ценностей в общество» [8, с. 115]. С этой точки зрения историко-правовые исследования - это определенный вклад в изучение интеллектуальной истории человечества: «Изучение языков мира - это также всемирная история мыслей и чувств человечества» [6, с. 349]. Кодексы концентрируют высшие достижения не только правовой мысли, но и развития языка: «Сохранив свою юридическую силу до наших дней, Кодекс (Наполеона) является не только действующим нормативно-правовым актом, регулирующим разные правоотношения, возникающие во французском обществе, но и глубоким источником французской языковой культуры, о чем неоднократно свидетельствовали многие писатели 19 века. Более того, цитаты, взятые из различных статей Кодекса, до сих пор широко используются практически во всех общелингвистических словарях» [3, с. 12]. Значение принятия Кодекса Наполеона выходит далеко за пределы французской правовой, языковой, политической культуры - количество стран, право которых прямо или опосредованно претерпело влияние Кодекса Наполеона, исчисляется десятками - в Европе, Африке, Северной Америке, Латинской Америке, Азии [3, с. 11]. «Глубокое знание положений Кодекса Наполеона, без сомнения, даст также верный ключ к пониманию и эффективному усвоению основных положений гражданского законодательства практически всех государств, так или иначе воспринявших Кодекс Наполеона, что может иметь практическое значение для лиц, соприкасающихся в своей деятельности с законодательством различных государств мира» [3, с. 3].

Современная наука не исчерпала заложенные в 19 веке методологические подходы и приемы гуманитарных наук, дальнейшее их развитие способствует обогащению исследовательского инструментария общественных наук на современном этапе. История права позволяет выявить общие закономерности, причинноследственные связи между историческими явлениями и их рефлексией в праве, воздействие права на общественные отношения, что в свою очередь находит отражение в языке. Изучение взаимосвязи и взаимозависимости разных способов соционормативного регулирования позволяет экстраполировать предыдущий опыт на будущее время, заранее прогнозировать, направлять или избегать те или иные тенденции. История права, пользуясь методологией гуманитарных наук, позволяет установить связь специально-правовых исследований с другими общественными науками, вписать их в более объемную и многомерную картину мира, дать более целостное представление об обществе.

$$
\text { *** }
$$

1. Амосова Т.В., Юрковский А.В., Юрковская Е.А. Конвергенция юридических и линглвистических методов в сравнительном правоведении: юридическая компаративистская лингвистика // Вопросы российского и международного права. 2016. № 9. С. 96-107.

2. И.А. Власенко. Роль А.А. Ушакова в формировании отечественной правовой лингвистики//Государство и право. N 5. 2009. с. 86-92.

3. Гражданский кодекс Франции (Кодекс Наполеона)/ Пер. с франц. В. Захватаев/ Предисловие: А. Довгерт, В. Захватаев/ Приложения 1-4: В. Захватаев./ Отв. Ред. А. Довгерт. - Киев. 2006.

4. Гражданское уложение Германии: Вводный закон к Гражданскому уложению = Bürgerliches Gesetzbuch Deutschlands mit Einführungsgesetz; пер. с нем./ [В. Бергманн, введ., сост.]; науч. Ред. Т.Ф. Яковлева. - 4-е изд., перераб. - М. 2015. (Серия Германские и европейские законы; кн. 1).

5. В. фон Гумбольдт. Избранные труды по языкознанию. Перевод с нем. яз. под ред., с предисловием д.фил.н. Г.В Рамишвили. М. 1984.

6. В. фон Гумбольдт. Язык и философия культуры. М. 1985.

7. Н.Г. Павлова. Правовые традиции в сравнительном правоведении./Правовые традиции. Жидковские чтения: материалы Международной научной конференции. Москва. 29-30 марта 2013 г. Под ред. Г.И. Муромцева, М.В. Немытиной. - Москва: РУДН. 2014. С. 111-118.

8. Супатаев. О постижении и познании правовых явлений. Становление цивилизационного подхода к праву.//Труды Института государства и права РАН. N 1 (53). 2016. С. 90-120. 